\title{
THE INTERNATIONAL LAW ON THE PROTECTION OF CULTURAL HERITAGE
}

\author{
Katerina Papaioannou \\ University of Patras, GREECE, papaioannou.kat@gmail.com
}

\begin{abstract}
We present a comprehensive analysis of the concept of cultural heritage and the institutionalisation of its protection by the international law in various historical contexts of involved states, i.e., during peace, conflict, social and/or political crisis. Furthermore, we discuss the human dimension of the protection of cultural heritage at an international level under the public international law. In particular, we first investigate whether states remain central actors at national and international level as far as the protection of cultural property within their territory is concerned. Subsequently, we examine the limitations imposed on the action range of a state due to primary and secondary legislation of international organizations where the state participates. Apart from this form of external pressure on the state jurisdiction, we also examine whether the action range of a state is further limited by the action of individuals and groups. Furthermore, we discuss on the potential role of international human rights law in such situations, the interdependence between the protection of individuals and cultural goods as well as whether the individual is transformed into an active actor of international law.

Our analysis clearly suggests that international organizations play a catalytic role in cultural protection at an international level, with UNESCO holding a leading position. UNESCO forms a central processing mechanism for international protection standards and seems to be the main forum for monitoring compliance of states with international protection standards. However, an issue that certainly deserves further investigation is whether UNESCO can be actually efficient in the absence of ratification mechanisms regarding cultural protection.

Our approach and methodology involves thorough analysis of concepts, review of historical developments in international law regarding the protection of cultural heritage, review of the activities of international organizations as well as the description of the existing legal framework. Results of our study suggest that the issue of cultural heritage protection is multidimensional and involves not only states but also individuals who are holders of rights and obligations regarding cultural heritage protection. In addition, our results clearly imply that there is still room for improvement in the continuously evolving international law towards the establishment of a more satisfactory framework for the protection of cultural heritage.
\end{abstract}

Keywords: cultural heritage, international law, protection of cultural heritage. 


\section{INTRODUCTION}

From its dawn and throughout its evolution over time, humanity has presented works and progress highly dependent on the degree of cultural development. Culture has followed a constantly upward trajectory mainly due to the strong will of subsequent generations to protect, preserve, maintain and develop the cultural property delivered to them by their ancestors. However, a structured and organized approach to the value of cultural heritage through the systematic study of cultural works of the past dates back to the Renaissance, i.e., 15th and 16th century. Rapid progress and more systematic approaches to elements constituting cultural heritage as well as to issues regarding the protection of cultural property and the establishment of international rules primarily aimed at regulating cultural heritage took place no later than the end of the 19th century and continued during the $20^{\text {th }}$ century, especially in the light of significant losses resulted from the two World Wars.

In the following, we report on the international effort for creating rules of law covering issues of cultural heritage. While there is a long literature on legal issues related to cultural heritage, our study suggests an innovative approach in the sense that we do not just provide a list of relevant but we also present and analyze the actual multilateral effort of the international community to guard cultural heritage. Our objective is to highlight the fact that during the second decade of the 21 st century international protection of cultural heritage in the context of public international law has acquired a human dimension. The legal basis for the protection of cultural heritage has been significantly influenced by the international law of human rights. In this new humanitarian order, there exists a bidirectional relationship between individuals and the protection of cultural heritage. In such a setting, individuals become actors of international law and therefore have rights and obligations regarding the protection of cultural heritage. Thus, protection of cultural heritage is a multidimensional issue which does not only involve states but also individuals.

The rest of the paper is structured as follows. In Section 2, we present the definition of cultural heritage. In Section 3, we describe in detail how cultural heritage as well as its protection and preservation is addressed in international law, during periods of armed conflict and peace. Concluding remarks are presented in Section 4 .

\section{DEFINITION OF CUTURAL HERTITAGE}

Cultural heritage is defined as the legacy of cultural property along generations in order to maintain and exploit it and to further deliver it to future generations. More precisely, the definition of cultural heritage is trifold: Cultural Heritage is composed of Tangible Cultural Heritage, Intangible Cultural Heritage and Natural Heritage. Tangible Cultural Heritage includes all tangible cultural goods including (i) movable cultural heritage, e.g., paintings, sculptures, coins, manuscripts, etc., (ii) immovable cultural heritage, e.g., monuments, archaeological sites, etc. and (iii) underwater cultural heritage, e.g., shipwrecks, underwater ruins and cities, etc. Intangible Cultural Heritage includes knowledge and techniques as well as tools, crafts and cultural places associated with them, representations, expressions and practices which can be recognized by communities, groups and, in some cases, individuals as part of their cultural heritage. More specifically, intangible cultural heritage include oral traditions and expressions, linguistic and artistic cultural heritage, social practices, rituals and festivities, knowledge and practices concerning nature and the universe as well as know-how linked to traditional crafts. Natural Heritage includes all natural monuments which may consist of various physical and biological formations. It further includes geological and physiographic formations and areas where biodiversity (flora and fauna) develops. Finally, it refers to all natural landscapes of global scientific value or of particular natural beauty.

\section{CULTURAL HERITAGE AND INTERNATIONAL LAW}

Since the mid- $17^{\text {th }}$ century the international community has felt the need for protecting their cultural goods as well as for the existence of international laws for this purpose, initially during a time of war. The first legislative regulation in a European country dates back to 1666 in Sweden with the enactment of such a law for the protection of their national monuments. By the end of the $19^{\text {th }}$ century the majority of the rest of the European countries will have followed with the implementation of laws for the protection of their archeological and historical heritage. In America in 1863 the "Lieber Code" was the first attempt for implementing rules during a time of war for the protection of cultural goods; it resulted as the basis for the Brussels Declaration in 1874, the first international codification. It was never adopted though due to the reaction of Great Britain.

Destruction, sale or snatching of monuments and works of art has traditionally been a part of the ideology of war. The winners were often driven to looting and quite frequently to the destruction of national and cultural symbols as a way of punishing the losers. By using, as a basis, the "Lieber Code" and the Declaration of 
Brussels, the first official agreements -The Hague Conventions of 1899 and 1907- were set up for such issues as the protection of cultural goods. Despite the implementation of those specific provisions the protection of cultural goods was never secured. During the two World Wars the damages inflicted upon the international cultural heritage were incalculable. Historical monuments and temples were destroyed; books and manuscripts that were kept in libraries were lost since those buildings were burnt down; many other historical monuments and cultural goods were lost as well.

The international community realized that existing legal regulations were insufficient for the protection of cultural heritage, thereby setting forth an active search for the creation of a more efficient system of protection on an international and national level. Characteristic is the emergence and activity of International Organizations such as UNESCO (United Nations Educational, Scientific and Cultural Organization), a body under the auspices of United Nations dedicated to Education, Science and Culture. The purpose of its foundation is to be a global laboratory of ideas and to play a regulatory role for the promotion of international collaborations. UNESCO called a meeting in Hague in April and May of 1954, which led to the signing of the "Convention for the Protection of Cultural Property in the Event of Armed Conflict". This was the first systematic effort during the postwar period for the protection of cultural heritage. However, it did not regulate the issue of unlawful exportation of cultural goods that were removed during armed conflict, resulting in the addition of the First Protocol. The issue of the "return of cultural property" was not included in the text of the Convention, hence becoming a point of friction. Even though it was supported that its non-inclusion was due to the fact that the Convention referred to the protection of cultural goods only during times of armed conflict, whereas the issue of returning stolen goods is placed after the end of hostilities, the argument was weakened due to the existence of articles within the Convention on the protection of cultural goods both during times of peace - Art. 3 and 7 of the Convention - as well as during times of military occupation - Art. 5 of the Convention.

\section{LEGAL FRAMEWORK FOR THE PROTECTION OF CULTURAL HERITAGE DURING PERIODS OF ARMED CONFLICT}

The progressive development of the laws of armed conflict led to the simultaneous modernization of existing framework for the protection of cultural heritage during periods of armed conflict; specifically, Protocols I and II of 1977 to the Geneva Convention of 1949. Protocol I deals with international armed conflicts and Protocol II with non-international armed conflicts. It is worth noting that art.53 of Protocol I relating to cultural objectives and areas prohibits any kind of hostile act against historical monuments, works of art, or places of worship which constitute cultural or spiritual heritage of peoples as well as their use in any military effort or use of them as the subject of retaliation. It basically covers the same idea of protection as Art. I of the 1954 Hague Convention, but the obligation appears much more stringent, both in relation to the obligation resulting from the Hague Convention and from that resulting from the 1907 Hague Regulations. This protocol contains no deviation, even for reasons of military necessity. Only if the warring parties are included in both the Hague Convention of 1954 and in the Additional Protocol I, does the possibility of invoking military necessity exist. While Art.52 relates to the protection of civil targets and, by extension, of the cultural goods not covered by Art.53. According to this, attacks must be strictly limited to military objectives while urban targets should not be made the object of attack or reprisals. Finally and importantly, the content of Art.85, which recognizes the action of intentionally attack against historic monuments, works of art or places of worship as a war crime. An exception is recognized only in the event of proximity of a cultural object to military objectives, or if a specified cultural object is used somehow in a military effort. In this way, the possibility of appeal is given to international courts in case of protocol violation. Protocol II of the Geneva Convention of 1977, as already mentioned above, covers non-international armed conflicts. In particular Art.16 refers to culture. It reiterates the prohibition of committing hostile acts against historic monuments, works of art or places of worship which constitute the cultural or spiritual heritage of peoples, and their use in support of military efforts. This Protocol, leaves outside its own boundaries isolated and sporadic acts of violence and a number of similar types of internal unrest. However there have been cases of internal conflict which eventually received an international character, for which the way the Protocol was applied has been disputed.

In conclusion, through the disputed articles of the above mentioned protocols, a specific legal framework has been established which determines a typological criterion for the protection of goods according to which historical monuments, works of art and places of worship must be distinctively treated and an evaluative criterion for the protection of goods which constitute the cultural and spiritual heritage of peoples. This protection applies only to objects of heritage closely linked to the subjective discretion of countries.

There are additional international conventions, which although not solely related to the protection of cultural property in the event of armed conflict, contain provisions succinctly stated in the International Covenant on 
Economic, Social and Cultural Rights, adopted in 1966 by the UN General Assembly. Although there is no explicit reference to culture, cultural rights are recognized as closely related to human rights. In addition to the UNESCO Convention of 1970 there is an attempt to control illegal international trade of cultural goods, as a plethora of movable cultural goods were taken from occupied territories. The UNESCO Convention of 1972 on the Protection of the World Cultural and Natural Heritage provided a Training list of World Heritage in danger. One of the greatest risks for cultural and natural heritage assets is an armed conflict already started or about to launch. Another international declaration that follows this direction is the Declaration of Dresden 1982 themed "Reconstruction of Monuments Damaged by War". Finally it is worth mentioning the Second Additional Protocol to the Hague Convention, which was adopted on March 26, 1999. In many cases, national conflicts which could not be included in international arrangements proved detrimental to cultural goods. So it was broadly accepted that existing regulations must be applied even to conflicts without international character; furthermore, cultural property must be transferred in emergency cases. This turn indicates a modernization of the existing framework and its subsequent adaptation to the 21 st century. In this way, together with the creation and evolution of a legal framework covering the issue of protection of cultural heritage in times of armed conflict, a legal framework for the protection of cultural heritage in times of peace was also induced.

\section{LEGAL FRAMEWORK FOR THE PROTECTION OF CULTURAL HERITAGE DURING PERIODS OF PEACE}

The major issue of the preservation of cultural heritage preoccupied the international community in general, i.e. in times of peace, because the threats were real and in no way restricted to only times of war. The ever worsening environmental conditions, climate change, illegal trafficking of cultural goods, acts of terrorism are some of the problems that can arise in peacetime.

After the foundation of UNESCO, Conventions began to be adopted in order to safeguard, preserve and protect cultural heritage at a worldwide level. The International Convention concerning prohibiting and preventing the illicit import, export and transfer of ownership of cultural property of UNESCO (1970) and the International UNESCO Convention on the Protection of the World Cultural and Natural Heritage (1972) were the central core around which cultural protection was formed. This framework was recently supplemented by the Convention on the underwater heritage signed in 2001 and the Convention on the Protection and Promotion of the Diversity of Cultural Expressions, signed in 2005. Equally important was the Convention for the Safeguarding of the Intangible Cultural Heritage signed in 2003. This includes new concepts and is a springboard for a more complete and balanced perception of humanity's cultural heritage.

Particular reference should be made to the 2003 UNESCO Declaration on the intentional destruction of cultural heritage which was unanimously adopted by all Member States of UNESCO. However, it does not constitute an obligatory legal document binding states at an international level. According to this 2003 Declaration, Member States commit to combat the intentional destruction of cultural heritage, both in wartime and in peacetime. In peacetime, states are strongly suggested to follow all international recommendations and conventions, while in time of war states are called upon to respect customary international law, international conventions and UNESCO recommendations. However, a highly important issue included in this Declaration is the recognition of responsibility on behalf of both States and individuals regarding destruction of cultural heritage: States bear responsibility for any intentional destruction of cultural heritage and individuals bear legal responsibilities for criminal activity involving cultural heritage.

International law together with state participation in international contracts imply a direct obligation of every state according to which internal rules of law must be in accordance with international requirements. Specifically, components constituting cultural heritage should be protected, as a whole or individually, by legislative or other regulatory measures. Therefore, each state has the obligation and the right to provide a legal definition of cultural goods.. The obligation stems from international documents and the right stems from sovereignty on cultural property situated in its territory. Also, each state is obliged to ensure preservation and non-destruction of its cultural heritage. This is a general principle that all states accept. An additional obligation refers to the preservation of cultural diversity that is safeguarding of all cultures. This issue is seen as particularly important and is especially highlighted due to relevant resolutions adopted by the UN General Assembly. Finally, if a State violates its international commitments on issues related to cultural heritage, criminal and administrative penalties are foreseen. It can be easily seen that there was an imperative the need for the establishment of international norms for the protection of cultural heritage in peacetime. So far, there have been considerable efforts in this direction but there is still several room for improvement due to the increasingly urgent need to protect cultural heritage and also due to new sorts of challenges. 


\section{MANAGEMENT OF CULTURAL HERITAGE IN PERIODS OF SOCIO-POLITICAL CRISIS}

Nowadays, while many countries show signs of social and political crisis, or are even blighted by them, they are presented with risks arising from their cultural resources which are diverse and multidimensional. The instability of a country, taking the form a civil war at a typical, most devastating scenario, may threaten the cultural heritage but may also lead to a significant loss of parts of it. This is because such countries become isolated and close their borders thus complicating communication with state representatives for risk assessment and protection of cultural heritage while also preventing international organizations from supporting the protection of cultural heritage. Obviously, however, when speaking of endangered human lives, cultural heritage protection may well be considered as an issue of low priority.

Furthermore, during socio-political crisis, cultural heritage runs the risk of vandalism and looting even by internal population. It is also worth noting that it is impossible to protect the cultural heritage of a country in socio-political crisis via diplomatic or political means. Information exchange is only feasible among experts subject to local and national limitations. The creation of a local network of experts able to assess the value of cultural heritage would definitely help towards the rapid establishment of communication channels. Following a similar line, international organizations, e.g., UNESCO, could more efficiently communicate with local experts rather than rely on civilian administrations. In the special case when extremist groups threaten cultural resources for religious reasons, any political effort would be ineffective and would further increase the risk of attack. Instead, local experts could more easily deal with the problem identifying the perpetrators, trying to come up with resolutions and eventually accelerating the process of saving endangered cultural resources.

Public awareness is essential for efficiently facing issues related to cultural heritage protection. The organization of social activities by professionals working on cultural heritage as opposed to any type of administrative measures can play a catalytic role in preventing and healing the problem. This is because cultural heritage experts can organize public activities with an objective to raise awareness. Furthermore, due to their education, training and skills they can efficiently evaluate situations and propose adequate protection methods and course of action. In addition, they can communicate with international organizations and provide updated information since they either actively participate in them or are at least know how they work.

To sum up, under conditions of socio-political crisis due to people opposition to governments, cultural resources are highly threatened. Ignorance dominates regarding the multidimensional and multilateral value of cultural heritage as well as reasoning justifying its protection. The instability of regimes reduces the importance of cultural heritage protection issues compared to political issues. People incorrectly conceive destruction of cultural resources as a way to actively state their opposition against regimes. In addition, the action of international organizations is limited in period of crisis because their national committees are unable to function properly due to existing instability and also because regimes consider the structure of international organizations unreliable. In recent decades, socio-political crises have erupted in several countries in the Middle East and Africa with a direct impact on the cultural wealth of the various countries in these regions of the Globe. It is reasonable, therefore, whenever such a crisis occurs - or there is an expressed fear that it will occur - it threatens all kinds of resources of the cultural heritage of that country.

\section{CONCLUDING REMARKS}

The protection of cultural property at an international level in the context of the public international law, going through its second decade of the 21st century and taking into account the nature and function of protected goods and their direct connection with individuals and groups, has acquired a human dimension which is not just a trend but a fact. Public international law, beyond the fact that it is constantly changing in order to address all emerging challenges, seeks to demonstrate the human dimensions of international protection of cultural heritage, while still considering the state as a central factor for the protection of cultural property within its territory at a national and international level. However, the power of States is limited by the pressure of the international community and the pursuit of common interests through international obligations of general and specific protection of conventional and customary character, stemming both from primary and secondary legislation of international organizations where States participate. Apart from this external pressure, jurisdiction of States is further limited by the action of individuals and groups. The legal basis for the protection of cultural heritage is greatly influenced by international human rights laws which have simultaneously created an additional legal basis.

In this new humanitarian order there is a bidirectional relationship between the individual and the protection of cultural goods. Individuals become actors of international law and therefore have rights as well as 
obligations for the protection of cultural heritage. This human dimension certainly does not limit the role of the State; on the contrary, it appoints additional protection obligations arising from international law of human rights and international humanitarian law. Under the pressure of individuals and groups States must also make the necessary steps towards the protection and preservation of individual cultural components which could be neglected otherwise.

The action of member states at a regional level - Europe, US and most recently Africa - leading to the development of regional agreements which haven't left cultural heritage laws unaffected must also be highlighted. Regional conventions which are completely in line with the global protection standards of UNESCO either play an additional role to the existing collaborations of member states or are intended to regulate specific aspects that enhance the protection of cultural heritage.

Despite institutional diversity regarding the protection of cultural heritage induced from the action of international and regional institutions, UNESCO maintains a leading role for the protection of cultural heritage at an international level being the main processing mechanism of international protection standards as well as the main forum for assessing member state compliance with international protection standards. However, UNESCO has been characterized as a "giant with clay feet" because of the lack of penalty mechanisms regarding cultural protection. Strengthening cooperation with institutions of the UN for the protection of cultural heritage could certainly help UNESCO effectively face several existing challenges.

In conclusion, protection of cultural heritage is a multidimensional issue that does not just apply to states but also to individuals who have rights and obligations towards cultural heritage protection as evidenced by international law. Individuals and groups have an active role in the protection of their cultural heritage. The global community has realized that coordination and mobilization of States and also groups and individuals therein can build an efficient framework for the protection of cultural heritage. The international community, exploiting the constantly evolving international law should remain coordinated and jointly tackle the problems that still exist towards the important objective of protection and preservation of the world culture.

\section{REFERENCE LIST}

Bassiouni, C. Reflections on Criminal Jurisdiction in International Protection of Cultural Property. Accessible to: http://surface.syr.edu/cgi/viewcontent.cgi?article=1148\&context=jilc Last retreived: 09/2015.

Beiraghi, M. (2012). Risk Preparedness and heritage management in times of sociopolitical crisis: The role of experts in Simon Lambert and Cynthia Rockwell, Protecting Cultural Heritage in Times of Conflict, ICCROM, Rome.

Carman, J. (2002). Archaeology \& Heritage. Continum, New York.

Forrest, C. (2002) "A New International Regime for the Protection of Underwater Cultural Heritage", International and Comparative Law Quarterly, Vol. 51, No. 3. Accessible to: http://www.austlii.edu.au/au/journals/UQLRS/2002/2.html. Last retrieved: 11/2015.

Harrison, R. What is heritage? Accessible to: https://www.academia.edu/776638/What_is_Heritage. Last retrieved: 08/2015.

Jacquard, A. (2006). Quelle UNESCO pour l'avenir, UNESCO. Accessible to: http://unesdoc.unesco.org/images/0014/001455/145580f.pdf. Last retrieved: 12/2015.

Merryman, J. H. Two ways of Thinking about Cultural Property. Accessible to: http://minervapartners.typepad.com/readings/MerrymanTWOways.pdf. Last retrieved: 09/2015.

Pilloud, C., Sandoz, Y., Zimmermann, B. (1987). Commentary on the Additional Protocols of 8 June 1977 to the Geneva Conventions of 12 August 1949. ICRC, Martinus Nijhoff Publishers.

Pressovyre, L. The past is not just made of stone. Accessible to: https://www.questia.com/magazine/1G177035063/the-past-is-not-just-made-of-stone . Last retrieved: 09/2015.

Raftopoulos, E., McConnell, M. (2014). Contributions to International Environmental Negotiation in the Mediterranean Context, edit. Law Library, Athens.

Seršić, M. (1996). "Protection of Cultural Property in Time of Armed Conflict", Netherlands Yearbook of International Law, vol. 27.

Strati, A. (1995). The Protection of the Underwater Cultural Heritage: An Emerging Objective of the Contemporary Law of the Sea, edit. Martinus Nijhoff Publishers, The Hague/London/Boston. 